\title{
Imaging the Plate Interface in the Cascadia Seismogenic Zone: New Constraints from Offshore Receiver Functions
}

\section{by Helen A. Janiszewski and Geoffrey A. Abers}

Online Material: Table of station parameters.

\section{INTRODUCTION}

The Cascadia subduction zone, where the Juan de Fuca (JdF) plate subducts beneath North America, has paleoseismic evidence of $M_{\mathrm{w}} \sim 9.0$ megathrust earthquakes (Nelson et al., 1995; Goldfinger et al., 2003). However, there are virtually no instrumentally recorded thrust-zone earthquakes, hence the location and behavior of the seismogenic zone is known only indirectly. Temperature has been proposed to control seismogenesis with depth, assuming that the locked zone extends from the trench or the $150^{\circ} \mathrm{C}$ isotherm down-dip to the $350^{\circ} \mathrm{C}$ isotherm, with a transition zone extending to $450^{\circ} \mathrm{C}$ (Hyndman and Wang, 1993; Oleskevich et al., 1999; Cozzens and Spinelli, 2012). These models generally place the down-dip edge of the locked zone near the coastline. Inversions of onshore Global Positioning System data also can be used to determine the locking behavior and place the locked zone offshore (e.g., McCaffrey et al., 2013).

Onshore receiver function $(\mathrm{RF})$ studies have imaged an eastward-dipping low-velocity zone (LVZ) with high $V_{P} / V_{S}$ between the coastline and depths of $45 \mathrm{~km}$ (Rondenay et al., 2001; Nicholson et al., 2005; Abers et al., 2009; Audet et al., 2009). This structure has been interpreted as overpressured pore fluids, metamorphosed sediments, or a combination thereof at or just above the top of the subducting oceanic crust (Abers et al., 2009; Hansen et al., 2012). Because of this uncertainty, it is unclear if an LVZ should continue up-dip through the locked zone, since fluid pressure and metamorphism should vary differently with depth (e.g., Hacker et al., 2003; Liu and Rice, 2007; Saffer and Tobin, 2011). However, existing RF images only sample the plate boundary deeper than the locked zone because past broadband arrays are on land. Brillon et al. (2013) analyze RFs from two ocean-bottom seismometers (OBSs) offshore of Vancouver Island, but poor data quality at these stations contributes to large uncertainties.

Receiver funtions are difficult to calculate from OBS instruments, because water column multiples interfere with other arrivals and noise is high particularly on horizontal components (Leahy et al., 2010; Bostock and Trehu, 2012; Ball et al., 2014). The Cascadia Initiative (CI) is a prime opportunity to revisit this challenge (Toomey et al., 2014). In particular, the new trawlresistant-mount (TRM) OBS design not only allows the instruments to be deployed in shallow water, but also greatly reduces horizontal-component noise (Webb et al., 2013). In this article, we evaluate the ability of all sites of the CI array to calculate RFs, and we focus on results from the 19 OBSs deployed off the coast of Grays Harbor, Washington. These extend the onshore Cascadia Arrays for Earthscope (CAFE) broadband array (Abers et al., 2009) offshore, allowing direct comparisons.

\section{DATA PROCESSING}

\section{Instrument and Data Selection}

During years 1 (2011-2012) and 3 (2013-2014) of the CI, seismometers were deployed in an array with $\sim 70 \mathrm{~km}$ station spacing covering the northern section of the JdF plate and a dense $(\sim 10 \mathrm{~km})$ spacing on a transect near $47^{\circ} \mathrm{N}$ over the thrust zone (Fig. 1). This Grays Harbor focus site (GHFS) is mostly in $<900 \mathrm{~m}$ of water (ㅌ) Table S1, available in the electronic supplement to this article), where most instruments are of the TRM design.

Earthquakes are analyzed between $20^{\circ}$ and $100^{\circ}$ from the array with $M_{\mathrm{w}}>6.0$. The orientation of the horizontal axes of OBS instruments is unknown on the seafloor and is calculated after recovery, initially using the orientations supplied by the Ocean Bottom Seismograph Instrument Pool (OBSIP) Management Office (OMO; Lodewyk et al., 2014). These are then rotated into the vertical-radial-transverse (ZRT) coordinate system for each earthquake and filtered with a $0.1 \mathrm{~Hz}$ high-pass filter (two-pole Butterworth) to remove noise associated with infragravity waves (Crawford and Webb, 2000). Filtered signals are analyzed if they have visible $P$ waves with maximum absolute amplitude during the first $15 \mathrm{~s}$ that are at least twice that of the pre-event noise (from 5 to $30 \mathrm{~s}$ before the $P$ wave) on the $Z$ component and 1.25 times on the $R$ component. Based on these criteria, the OBSs recorded 52 earthquakes suitable for RF calculation; however, due to variations in deployment time and signal quality, individual stations used only a subset of these earthquakes (Fig. 1). Coverage is mostly restricted to three back azimuths: $\sim 120^{\circ}-150^{\circ}$ from Central and South America, 


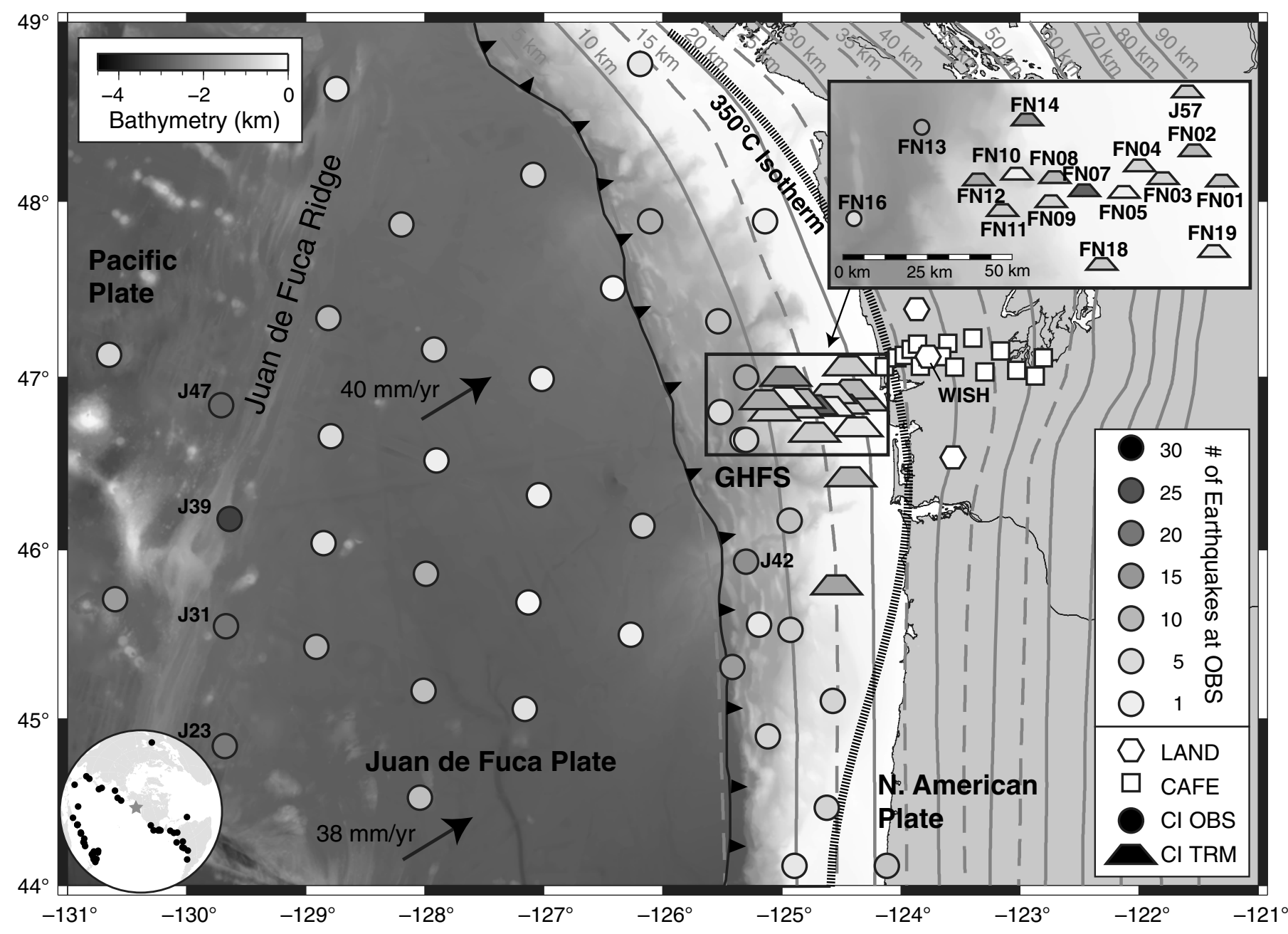

$\Delta$ Figure 1. Locations of ocean-bottom seismometer (OBS) stations used in this study (Cascadia Initiative [CI OBS] and CI Trawl-ResistantMount [CI TRM] OBSs), selected onshore stations (Cascadia Arrays for Earthscope [CAFE]; Abers et al., 2009), and onshore stations that operated simultaneously with the OBSs (LAND). The OBSs are shaded according to the number of RFs calculated. Solid gray contours indicate the depth to the top of the subducting crust in $10 \mathrm{~km}$ increments; dashed lines indicate $5 \mathrm{~km}$ increments (McCrory et al., 2012). The thermal estimate of the down-dip limit of the locked zone is shown as the contour of the $350^{\circ} \mathrm{C}$ isotherm (Cozzens and Spinelli, 2012). Juan de Fuca (JdF)-North America plate motion is from DeMets et al. (1994). The Grays Harbor focus site (GHFS) is indicated within the black box shown at the top right. (Bottom left inset) Teleseismic events recorded for this study.

$\sim 220^{\circ}-240^{\circ}$ from the southwestern Pacific, and $\sim 270^{\circ}-300^{\circ}$ from Japan and the Aleutians (Fig. 1, inset). We also calculate RFs during the same time period at three nearby onshore stations for data quality comparison (e.g., hexagons in Fig. 1).

\section{Receiver Function Calculation}

The time-domain iterative deconvolution method (Ligorria and Ammon, 1999) is used to calculate radial-component RFs for selected earthquakes. Signals are filtered with a low-pass Gaussian filter of the form $\exp \left[-0.5\left(f / f_{c}\right)^{2}\right]$, in which $f$ is the circular frequency and the corner frequency $f_{c}$ varies from 0.2 to $0.4 \mathrm{~Hz}$. Although we calculate RFs throughout the entire array, the shallow-water TRM OBSs are more straightforward to interpret as crustal structure due to their noise spectra and deployment location. At shallow-water stations, there is low coherence between the pressure and vertical components in the $0.1-0.4 \mathrm{~Hz}$ passband, indicating there is little noise from infragravity waves or other higher-frequency microseisms (Fig. 2a). Removal of tilt and compliance noise (e.g., Bell et al., 2014) does not improve signal quality, presumably because of this low coherence. Also, in shallow water, the water multiples are filtered out at the frequencies used. No effect on RFs is predicted for water up to $250 \mathrm{~m}$ deep, and significant additional arrivals only occur at water depths $>1 \mathrm{~km}$ (Fig. 2b). Because the TRM stations from the GHFS are all in shallow water, no additional processing is applied. We also present results from sites at the JdF ridge that are not corrected for tilt and compliance for comparison, but we do not interpret their crustal structure.

\section{OBS Instrument Orientation}

The horizontal orientations from the OMO are determined by Rayleigh-wave polarization (Stachnik et al., 2012) and have re- 
(a)

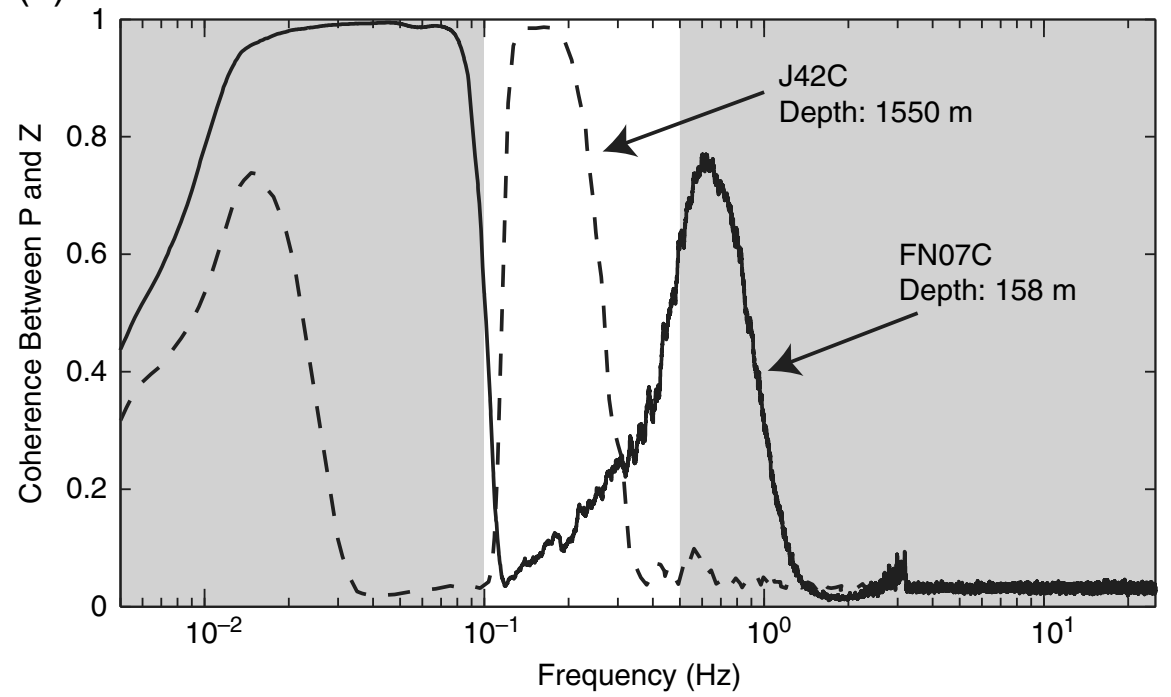

(b)

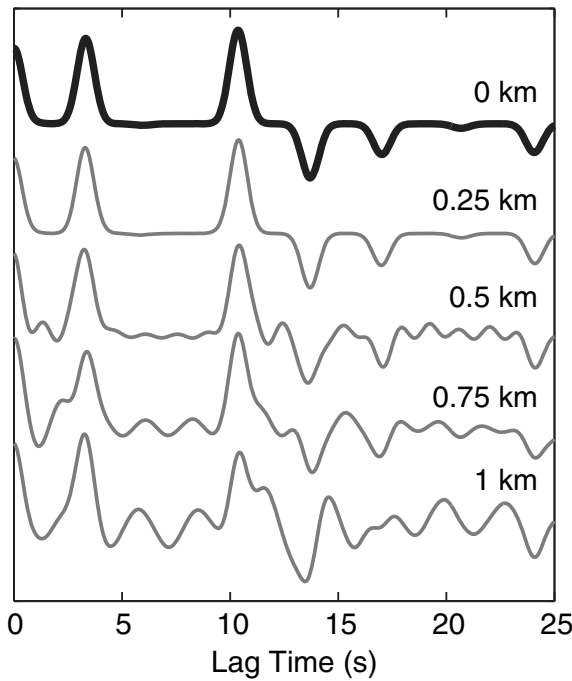

A Figure 2. (a) Comparison of coherence between the pressure $(P)$ and vertical $(Z)$ components at a shallow-water TRM (solid) and a deep-water OBS (dashed); water depths are labeled. The white area shows the nominal passband used for the receiver functions. (b) Synthetic RFs generated for a Moho boundary at $16 \mathrm{~km}$ depth with no water layer (black) and different water layer thicknesses (gray) filtered at $0.4 \mathrm{~Hz}$. Water depths are given on the right. The RF at a water depth of $0.25 \mathrm{~km}$ is indistinguishable from an absent water layer.

ported uncertainties up to $\pm 80^{\circ}$ at stations in the GHFS (Lodewyk and Sumy, 2014; Lodewyk et al., 2014). We compare these with orientations estimated from the RF calculation. In an isotropic medium with flat boundaries, the transverse-component RF will show only uncorrelated noise. This relationship can be complicated by anisotropy and dipping boundaries (Cassidy, 1992; Savage, 1998), but those signals have polarity and amplitude that vary with back azimuth. The correct back azimuth should be the one that minimizes transverse-component RF energy. We calculate the radial and transverse RFs rotating the coordinate system from $0^{\circ}$ to $360^{\circ}$ in $5^{\circ}$ increments, stacking the RFs for all usable earthquakes. The power in the first $5 s$ is calculated, and the orientation with the minimum transverse power corresponding to positive-amplitude radial arrivals is selected. The 95\% confidence bounds are calculated using an $F$-test, with degrees of freedom determined from the net filter response of the signal, similar to Silver and Chan (1991).

The orientations calculated for the GHFS have an average formal uncertainty of $\pm 10^{\circ}$, compared with $\pm 47^{\circ}$ reported by the OMO for these same stations. Of the 19 stations, 13 of the OMO estimates lie outside the $95 \%$ confidence bounds of the RF orientations. The median absolute difference between the OMO and RF orientations is $17^{\circ}$, with the largest differences at stations that have less than six RFs; the others agree to within $13^{\circ}$ on average. Given the apparent smaller uncertainties, we use this method to determine OBS orientations. (E) We provide orientations for all of the useable OBSs using this method in Table S1.

\section{VELOCITY CONSTRAINTS ON RFS}

We use existing seismic-velocity constraints to evaluate RFs. Several $P$-wave velocity images of the $\mathrm{JdF}$ plate and subduction zone show that the JdF crust is consistently $\sim 6 \mathrm{~km}$ thick prior to subduction, with $V_{P}$ in the upper $2 \mathrm{~km}$ of $5-6 \mathrm{~km} / \mathrm{s}$ and reaching up to $7 \mathrm{~km} / \mathrm{s}$ at the Moho (Flueh et al., 1998; Parsons et al., 1998; Gerdom et al., 2000). Flueh et al. (1998) imaged a region $25 \mathrm{~km}$ to the south and found average $V_{P}$ of the offshore forearc to be $3.7 \mathrm{~km} / \mathrm{s}$, reaching up to $5.4 \mathrm{~km} / \mathrm{s}$ just above the plate interface. Combining these estimates yields an average $V_{P}$ of $4.4 \mathrm{~km} / \mathrm{s}$ above the oceanic Moho. Onshore, $V_{P} / V_{S}$ of the overriding crust is 1.9 , and the $V_{P}$ and $V_{P} / V_{S}$ of the subducting oceanic mantle are 8.1 and $1.75 \mathrm{~km} / \mathrm{s}$, respectively, in this region (Parsons et al., 1999; Calkins et al., 2011; Hansen et al., 2012).

\section{RESULTS}

\section{Quality of Receiver Functions}

During year 1 of the deployment (July 2011-July 2012), 26 OBS stations recorded earthquakes that met criteria for RF calculation. During year 3 (July 2013-July 2014), this increased to 55 OBS stations due to improved instrument deployment and recovery methods. A total of 491 RFs were calculated. By combining RFs from stations that occupied the same site over the two deployments, we average $7.2 \mathrm{RFs}$ per TRM site and 6.7 RFs for other OBSs, with the three most successful sites averaging $24.0 \mathrm{RFs}$ (Fig. 1). RFs were also calculated at three nearby coastal stations (hexagons in Fig. 1) deployed during the same time period and using the same criteria for comparison; these averaged 108.3 RFs per station.

\section{Grays Harbor Focus Site (GHFS)}

Signals at the GHFS array exhibit consistent arrivals, both between individual RFs at single stations and between adjacent 


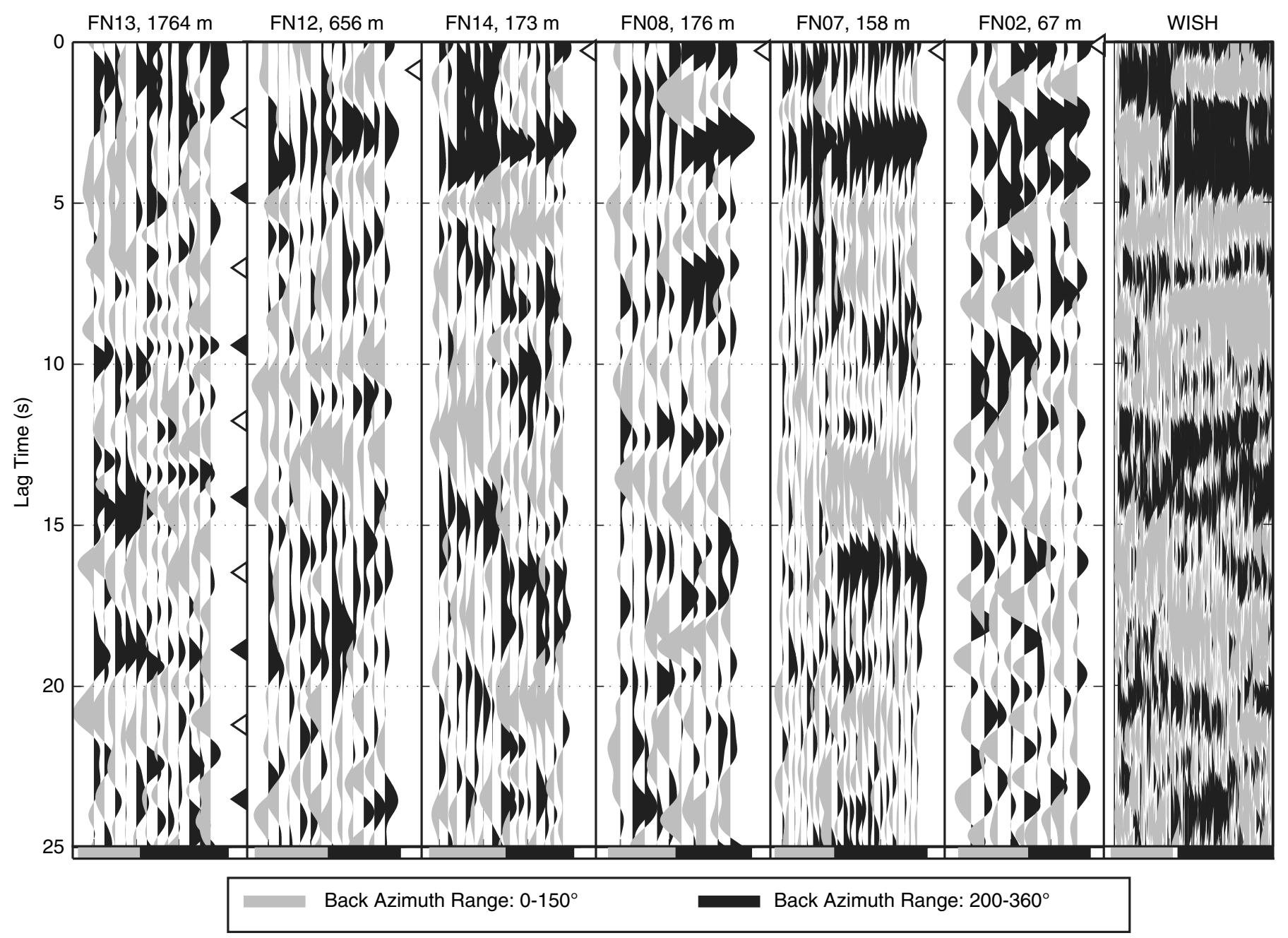

A Figure 3. Individual radial-component RFs from six GHFS locations and the onshore site WISH for comparison. At each site, RFs are sorted in increasing back azimuth to the right; bars at the base of each station underlie individual RFs that are from particular back-azimuth ranges. Positive arrivals are indicated in black, and negative arrivals are in gray. Sites are sorted with the westernmost at the left. FN13 is a deep water OBS, whereas others are TRM OBS; water depths are labeled. White triangles indicate times of predicted water multiples with negative polarity, and black indicates positive polarity. A Gaussian filter with a corner frequency of $0.4 \mathrm{~Hz}$ has been applied to all RFs.

stations for lag times less than 15-20 s (Fig. 3). Hence, these RFs are dominated by coherent signal. In most cases, these signals either do not show a zero-lag pulse representing the incident $P$ arrival or it is smaller than other peaks, such as typifies stations on low-velocity sediment (e.g., Sheehan et al., 1995). One of the highest amplitude arrivals observed at every shallow-water station is a positive pulse at $\sim 3 \mathrm{~s}$, which is observed consistently across back azimuths, with variation in the timing of the pulse up to $\sim 1 \mathrm{~s}$. Most stations show negative arrivals both before and after this $3 \mathrm{~s}$ peak, similar to features observed from the onshore station WISH, located along the GHFS-CAFE transect, for back azimuths $>200^{\circ}$ near 2 and $6 \mathrm{~s}$ lag (Fig. 3). This peak has been identified onshore as the upgoing $(P s)$ conversion package from the downgoing plate. Many of the OBS stations also have a broad negative pulse at $12-14 \mathrm{~s}$ that is similar in amplitude to the peak at $3 \mathrm{~s}$. In some cases, the timing (e.g., FN14) or amplitude (e.g., FN07) of this arrival varies with back azimuth (Fig. 3). The most successful sites in terms of RF data recovery were at $150-700 \mathrm{~m}$ water depths, but given the small number of stations it is not clear that depth is the main reason for the clearer signals. The water multiples at these depths arrive at a periodicity much shorter than the low-pass filter frequency (Fig. 3) so should have little effect. At sites in $<100 \mathrm{~m}$ of water (e.g., FN02), the signalto-noise ratio tended to decrease, fewer RFs were recorded, and some of the later arrivals are less visible. This is likely due to an increase in noise from direct wave loading on the station (Webb and Crawford, 2010). At FN12, the water column reverberations may have a minor effect on the RFs, based on sensitivity tests (Fig. 2b).

At OBSs deployed in $>1000 \mathrm{~m}$ of water (e.g., FN13; Fig. 3), arrivals exist that correlate between individual RFs, but these do not match any arrivals observed at the shallow-water stations. This may be due to a change in the structure, the appearance of water column multiples, or a combination of these effects. The primary water column multiples should alternate polarity, beginning with a negative arrival (Bostock and Trehu, 


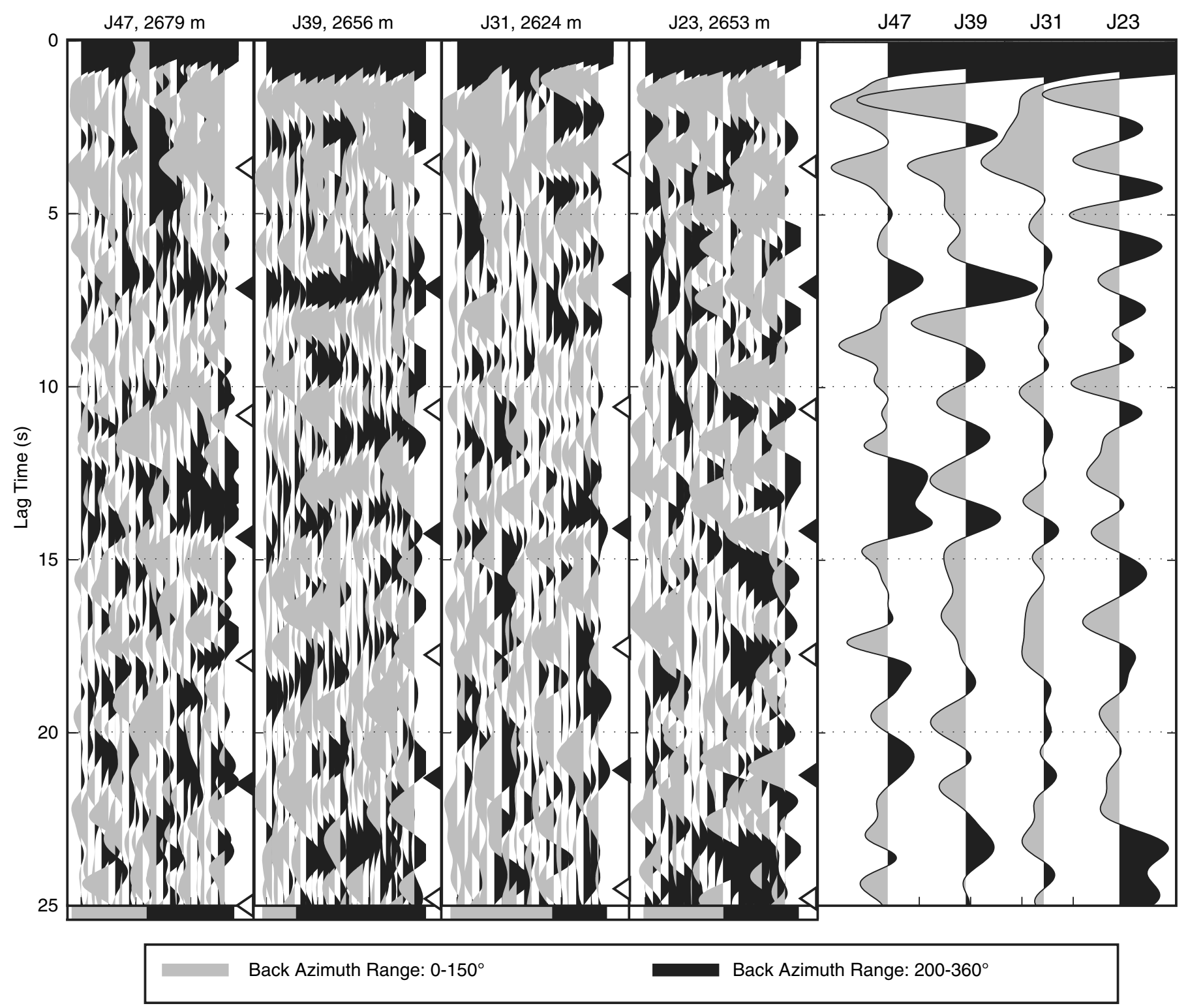

A Figure 4. Individual radial RFs from four sites near the JdF ridge, with stacks of these shown on the right. Format and processing are the same as in Figure 3.

2012) at times based on the depth (Figs. 3, 4). Reverberations generated by secondary phases may complicate this pattern, but the $P$-coupled multiples should be much larger than those generated by $P$-to- $S$ conversions.

\section{Juan de Fuca Ridge}

Several sites near the JdF ridge had high signal-to-noise ratios relative to those deployed in the center of the plate. These RFs consistently have a high-amplitude zero-lag peak, likely due to the thinner sediment (Fig. 4). Some arrivals are coherently observed between adjacent stations; however, we do not observe any across the array. Primary reverberations from the 6-km-deep oceanic Moho are not expected later than $\sim 4 \mathrm{~s}$, and the early signal may be explained by these. Several later coherent signals are likely water column reverberations.

\section{DISCUSSION AND CONCLUSIONS}

\section{Imaging the Plate Interface}

Receiver functions record the primary $P$-to- $S$ conversions and reflected multiples from seismic-velocity discontinuities (Fig. 5). Onshore, these signals are observed from the subducting oceanic Moho and from boundaries associated with the oceanic crust and plate interface (Abers et al., 2009; Audet et al., 2010; Hansen et al., 2012). We model the stacked RF from site FN07 as a stack of synthetic seismograms from plane-layered structures with ray parameters matching the observed RFs, leveraging prior information of velocities. At this location, the plate dips $\leq 5^{\circ}$, and the dip effects on seismograms should be minor.

Initially we test a simple two-layer model in which the upper layer has $V_{P}=4.4 \mathrm{~km} / \mathrm{s}$, consistent with averages of 


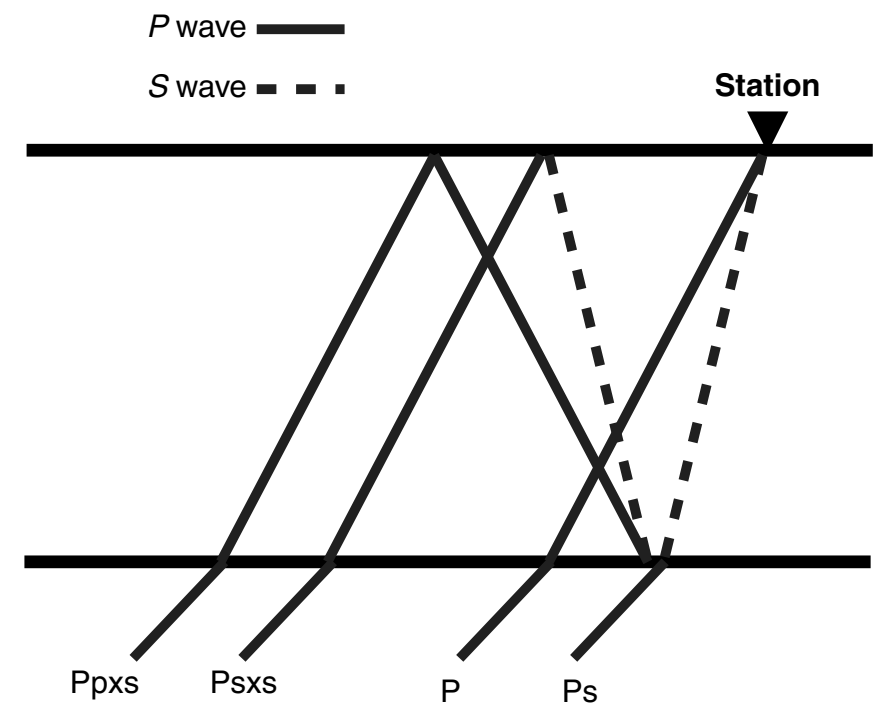

$\Delta$ Figure 5. Nomenclature used to describe the direct $(P s)$ and first surface-reflected (Ppxs, Psxs) RF arrivals.

nearby refraction models (Flueh et al., 1998) and $V_{P} / V_{S}=$ 1.9 as inferred onshore (Calkins et al., 2011). The $P s$ and $P s x s$ arrivals match a $15.8-\mathrm{km}$-deep interface, likely subducting Moho (Fig. 6a); hence, for $6 \mathrm{~km}$ of subducting oceanic crust, the plate interface would lie at $9.8 \mathrm{~km}$ depth. This is only $0.4 \mathrm{~km}$ shallower than the plate boundary inferred from Flueh et al. (1998); this difference could be explained by variations of the average $V_{P}$ or $V_{S}$ along strike by $\sim 3 \%$. Both are significantly shallower than the $14 \mathrm{~km}$ plate interface from McCrory et al. (2012). However, there are many features of the data that are not predicted by the synthetic RFs, most notably the predicted Ppxs multiple is weak in the OBS data. Our second model has a two-layered oceanic crust (Fig. 6b), which results in a reduced-amplitude Ppxs, but Psxs is also reduced.

We also test a model containing an LVZ, which better resembles the data (Fig. 6c). It features an LVZ from 6.5 to $9.5 \mathrm{~km}$ depth with $V_{P}=3.1 \mathrm{~km} / \mathrm{s}$ and $V_{P} / V_{S}=2.1$, overlying a 5 -km-thick oceanic crust layer with $V_{P}=5.9 \mathrm{~km} / \mathrm{s}$ and $V_{P} / V_{S}=1.97$, over oceanic mantle. This produces a reduced-amplitude $P$ pxs without reducing the $P s$ and Psxs amplitudes and at higher frequencies contains several smaller arrivals between 5 and $11 \mathrm{~s}$, similar to what is observed. The negative pulse at $14 \mathrm{~s}$ lag has contributions from both Ppxs and Psxs off different interfaces, interfering constructively. Although we did not exhaustively search the parameter space, any successful model that we tested included a low-velocity layer. The combination of the reduced Ppxs arrivals with a high-amplitude Psxs arrival is observed at several other GHFS stations (e.g., FN02, FN14; Fig. 6d), whereas other stations lack the pronounced (a)
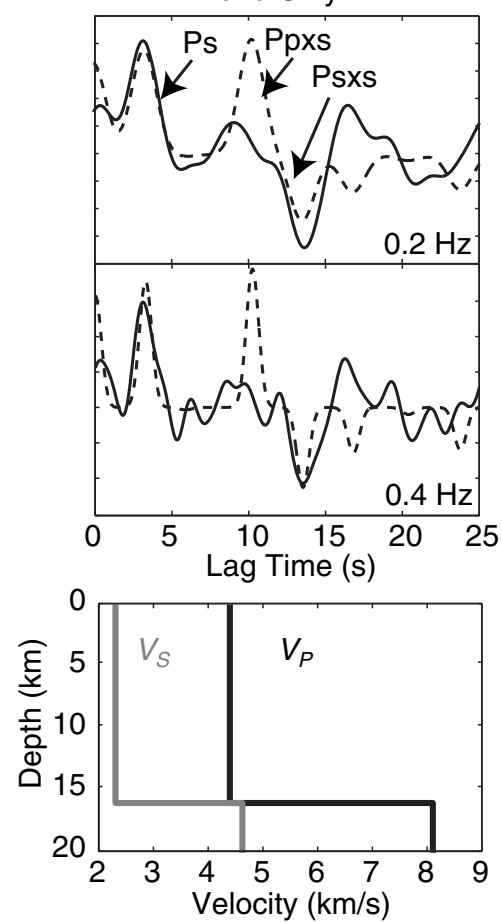

(b) Oceanic Crust
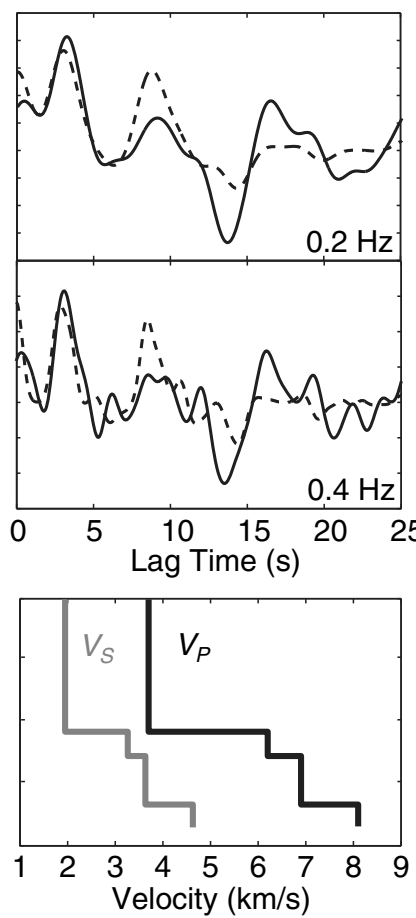

(c)
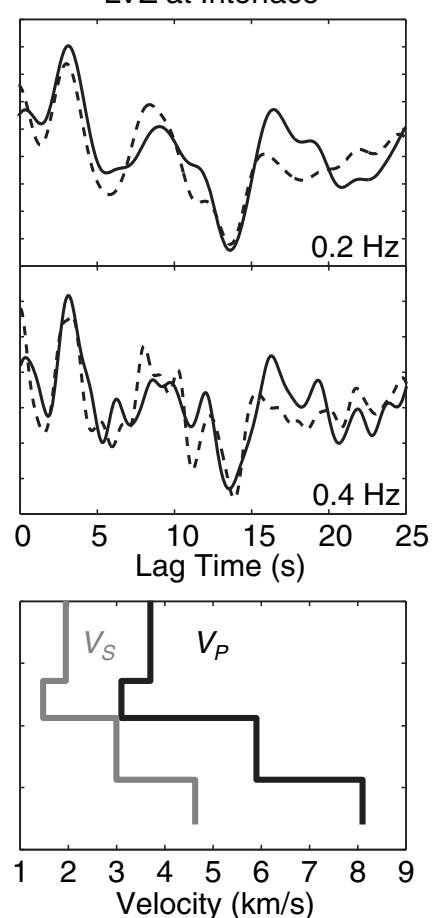

(d)

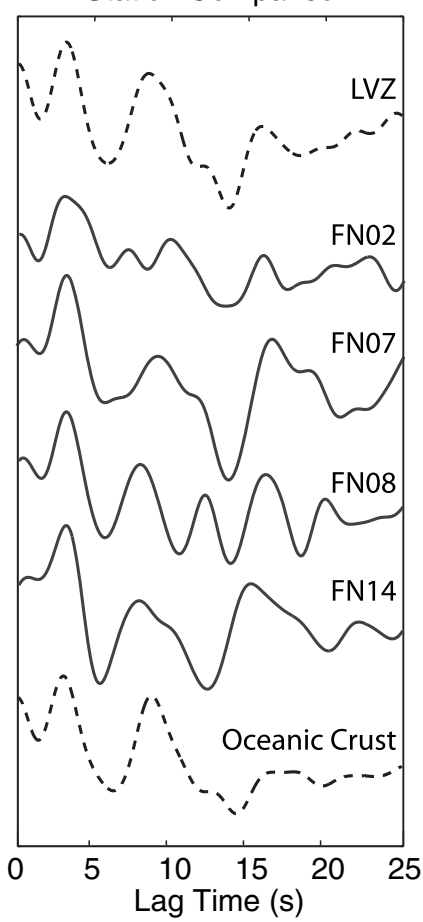

A Figure 6. Comparison of synthetic RFs with data for site FN07 for three velocity models: (a) single interface representing oceanic Moho, (b) multilayered subducted oceanic crust and thrust zone, (c) oceanic structure with LVZ at the plate interface, and (d) a comparison of data from additional stations with models (b) and (c). In (a-c): (top) comparison with $0.2 \mathrm{~Hz}$ low-pass filter, (middle) response with $0.4 \mathrm{~Hz}$ filter, and (bottom) the velocity models. The solid black line indicates data, and the dashed black line indicates synthetics. (d) Data from additional stations are compared with the synthetics from the LVZ model and the oceanic crust model at $0.2 \mathrm{~Hz}$. 
Psxs arrival (e.g., FN08; Fig. 6d). This may indicate structural variability; however, the similar observations at FN02, FN07, and FN14 indicate this feature may persist throughout the GHFS.

These forward models provide some indication of the origin of primary features in the RFs but do not include known variations in velocity in the upper plate and are inherently nonunique. Effects of very low near-surface velocities (e.g., Flueh et al., 1998; Parsons et al., 1998) are evident in the lack of a zero-lag pulse in the RFs but are not modeled here, so the first $2 s$ are not well matched. The assumption of constant upperplate velocities provides the correct timing of phases from the plate interface but will underestimate absolute velocities at the base of the layer, thereby overestimating the velocity contrast.

Nonetheless, these models show that the RFs from OBS are imaging structures from plate-interface depths and that the LVZ likely persists offshore. Because the upper-plate velocities are much lower offshore than onshore where mafic Siletz terrane rocks probably overlie the plate boundary (Trehu et al.,
1994; Parsons et al., 1999), the persistence of the LVZ requires very low velocities within the offshore thrust zone. The overriding plate has $V_{P}<5.4 \mathrm{~km} / \mathrm{s}$, so the $\mathrm{LVZ}$ must have velocities significantly lower and slower than nearby oceanic layer 2A (Flueh et al., 1998; Gerdom et al., 2000). In addition, offshore of Washington, the JdF crust is $6 \mathrm{~km}$ thick on average (Flueh et al., 1998; Gerdom et al., 2000), indicating that the 8$\mathrm{km}$-thick package of the LVZ and oceanic crust likely contains some overlying material.

\section{Offshore-Onshore Profile}

Station stacks of RFs from the onshore CAFE array (taken from Abers et al., 2009) and from the GHFS generate a profile that extends from the deformation front across the forearc. The arrivals previously identified as the $P s$ and $P$ sxs conversions from the oceanic Moho are continuous both onshore and offshore at 0.2 and $0.4 \mathrm{~Hz}$, except at the westernmost sites (Fig. 7). The onshore stations are characterized by a high-amplitude negative and positive Ppxs pulse from the top and bottom of the LVZ,
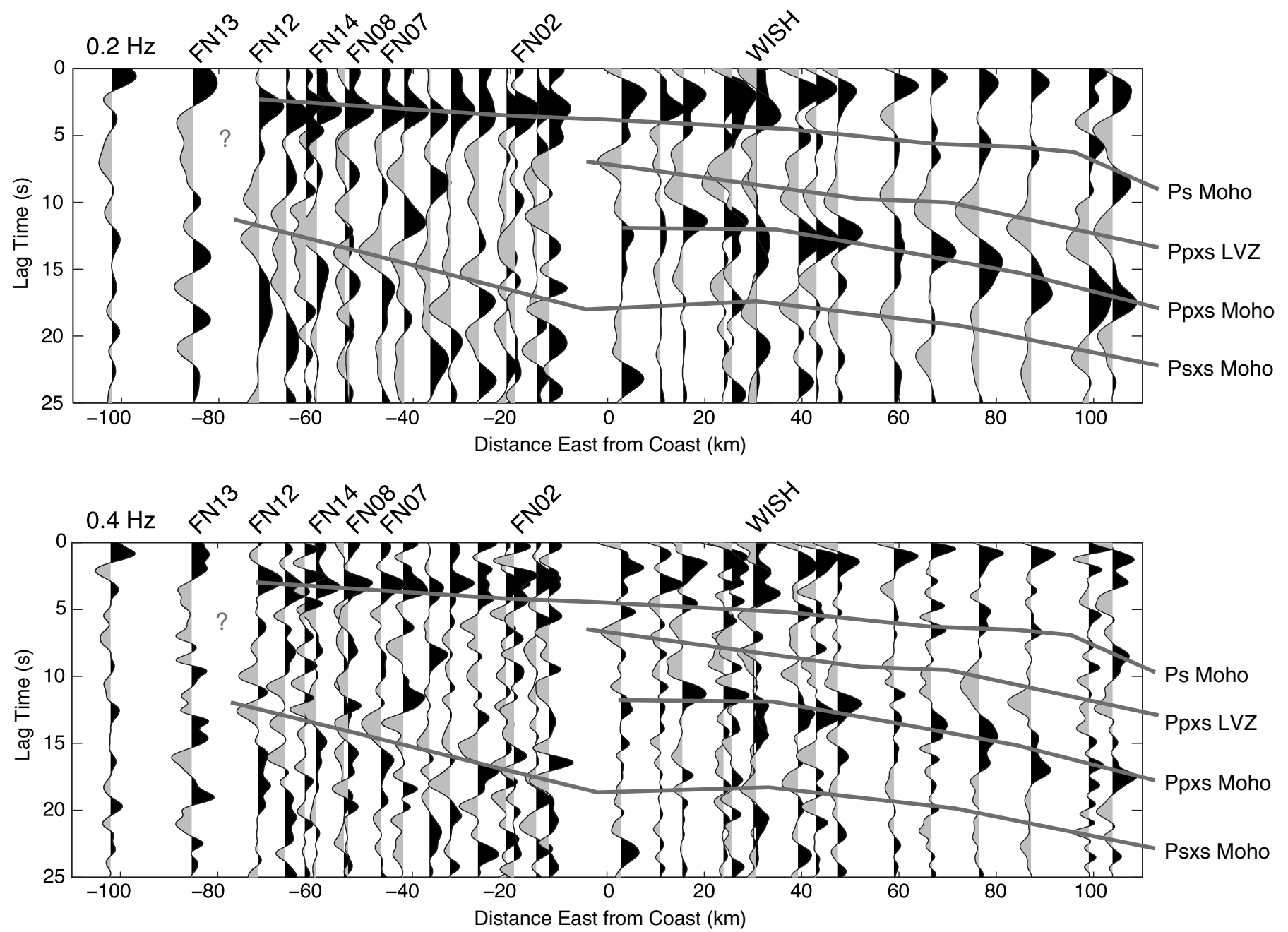

- Figure 7. Stacks of RFs plotted by distance along an east-west profile at $47^{\circ} \mathrm{N}$. Stations east of the coastline are in the CAFE array, and those west of it are in the GHFS OBS array. Identifiable arrivals discussed in the text are shown. (top) A Gaussian filter with a corner of $0.2 \mathrm{~Hz}$ is applied; (bottom) a $0.4 \mathrm{~Hz}$ corner is applied. 
respectively. These arrivals are not clearly observed on the OBS, whereas the later-arriving $P_{s x s}$ is clearer.

Results from forward modeling indicate these features are best explained by a velocity inversion at the plate interface using a shallower and slower structure than is observed onshore. The base of the overriding crust beneath the GHFS is expected to have $V_{P}=5.0-5.4 \mathrm{~km} / \mathrm{s}$ (Flueh et al., 1998; Parsons et al., 1999). Because modeling indicates a decrease of $\sim 0.5 \mathrm{~km} / \mathrm{s}$ in $V_{P}$ at the plate interface using the $V_{P} / V_{S}$ constraints described above, the LVZ beneath FN07 likely has $V_{P}=4.5-4.9 \mathrm{~km} / \mathrm{s}$, which is slightly slower than the $5.0 \pm 0.3 \mathrm{~km} / \mathrm{s}$ observed onshore (Abers et al., 2009). Similar observations of reduced velocities have been reported in the Nankai subduction zone approximately $10 \mathrm{~km}$ below sea floor (Kamei et al., 2012), similar to plate-interface depths observed in our study, and were interpreted as high-porosity underthrust sediment (Bangs et al., 2009). In addition, anisotropy could contribute to velocity reduction in the interplate shear zone, but we do not investigate this further. Nedimovic et al. (2003) observed an abrupt change in reflectivity moving up-dip offshore Vancouver Island, which might be manifest here as structural changes beneath the stations closest to the deformation front. However, structures within $5 \mathrm{~km}$ of the surface are hard to observe with RFs.

In summary, RFs can be calculated using data from OBS in forearc settings. The shielded TRM OBS exhibit low noise in the critical $0.1-0.4 \mathrm{~Hz}$ band, particularly on horizontal components. The offshore RFs from the GHFS record arrivals from a structure associated with the subducting oceanic crust, allowing continuous imaging of the plate interface nearly to the deformation front. Forward modeling indicates the subducting Moho is $\sim 16 \mathrm{~km}$ deep at FN07, located $\sim 45 \mathrm{~km}$ offshore of Grays Harbor; the precise depth depends on the overlying structure. Forward modeling also suggests that an LVZ at the zplate interface can explain several of the features observed in the RFs at this site, indicating that this structure may persist into the locked zone. $\mathbf{k}$

\section{ACKNOWLEDGMENTS}

This work is funded by National Science Foundation Award Numbers OCE-1334831 and EAR-1147622 and is based upon work supported by the National Science Foundation Graduate Research Fellowship under Grant Number DGE-11-44155. The offshore data used in this research were provided by instruments from the Ocean-Bottom Seismograph (OBS) Instrument Pool (http://www.obsip.org; last accessed November 2014), and the onland data are part of the EarthScope facility, both part of the Cascadia Initiative Amphibious Array funded by the National Science Foundation. All the seismic data are archived at the Incorporated Research Institutions for Seismology (IRIS) Data Management Center (http://www.iris.edu). We thank Spahr Webb for providing valuable insight into understanding the noise properties of the OBS instruments and Katie Keranen and Dana Peterson for providing stacking velocities from the Cascadia Open-Access Seismic Transects (COAST) cruise. This work benefitted from constructive reviews by Pascal Audet and an anonymous reviewer.

\section{REFERENCES}

Abers, G. A., L. S. MacKenzie, S. Rondenay, Z. Zhang, A. G. Wech, and K. C. Creager (2009). Imaging the source region of Cascadia tremor and intermediate-depth earthquakes, Geology 37, no. 12, 1119-1122.

Audet, P., M. G. Bostock, D. C. Boyarko, M. R. Brudzinski, and R. M. Allen (2010). Slab morphology in the Cascadia fore arc and its relation to episodic tremor and slip, J. Geophys. Res. 115, no. B00A16, doi: 10.1029/2008JB006053.

Audet, P., M. G. Bostock, N. I. Christensen, and S. M. Peacock (2009). Seismic evidence for overpressured subducted oceanic crust and megathrust fault sealing, Nature 457, no. 7225, 76-77.

Ball, J. S., A. F. Sheehan, J. C. Stachnik, F.-C. Lin, and J. A. Collins (2014). A joint Monte Carlo analysis of seafloor compliance, Rayleigh wave dispersion and receiver functions at ocean bottom seismic stations offshore New Zealand, Geochem. Geophys. Geosyst. 15, doi: 10.1002/2014GC005412.

Bangs, N. L. B., G. F. Moore, S. P. S. Gulick, E. M. Pangborn, H. J. Tobin, S. Kuramoto, and A. Taira (2009). Broad, weak regions of the Nankai megathrust and implications for shallow coseismic slip, Earth Planet. Sci. Lett. 284, 44-49.

Bell, S. W., D. W. Forsyth, and Y. Ruan (2014). Removing noise from the vertical component records of ocean-bottom seismometers: Results from year one of the Cascadia Initiative, Bull. Seismol. Soc. Am. 105, no. 1 , doi: $10.1785 / 0120140054$.

Bostock, M. G., and A. M. Trehu (2012). Wave-field decomposition of ocean bottom seismograms, Bull. Seismol. Soc. Am. 102, no. 4, $1681-1692$.

Brillon, C., J. F. Cassidy, and S. E. Dosso (2013). Onshore/offshore structure of the Juan de Fuca plate in northern Cascadia from Bayesian receiver function inversion, Bull. Seismol. Soc. Am. 103, no. 5, 2914-2920.

Calkins, J. A., G. A. Abers, G. Ekstrom, K. C. Creager, and S. Rondenay (2011). Shallow structure of the Cascadia subduction zone beneath western Washington from spectral ambient noise correlation, J. Geophys. Res. 116, no. B07302, doi: 10.1029/2010JB007657.

Cassidy, J. F. (1992). Numerical experiments in broadband receiver function analysis, Bull. Seismol. Soc. Am. 82, 1453-1474.

Cozzens, B. D., and G. A. Spinelli (2012). A wider seismogenic zone at Cascadia due to fluid circulation in subducting oceanic crust, Geology 40, no. 10, 899-902.

Crawford, W. C., and S. C. Webb (2000). Removing tilt noise from low frequency $(<0.1 \mathrm{~Hz})$ seafloor vertical seismic data, Bull. Seismol. Soc. Am. 90, no. 4, 952-963.

DeMets, C., R. G. Gordon, D. F. Argus, and S. Stein (1994). Effect of recent revisions to the geomagnetic reversal time scale on estimates of current plate motions, Geophys. Res. Lett. 21, 2191-2194.

Flueh, E. R., M. A. Fisher, J. Bialas, J. R. Childs, D. Klaeschen, N. Kukowski, T. Parsons, D. W. Scholl, U. ten Brink, A. M. Trehu, and N. Vidal (1998). New seismic images of the Cascadia subduction zone from cruise SO108-ORWELL, Tectonophysics 293, 69-84.

Gerdom, M., A. M. Trehu, E. R. Flueh, and D. Klaeschen (2000). The continental margin off Oregon from seismic investigations, Tectonophysics 329, 79-97.

Goldfinger, C., C. H. Nelson, and J. E. Johnson (2003). Deep-water turbidites as Holocene earthquake proxies: The Cascadia subduction zone and northern San Andreas fault systems, Annu. Rev. Earth Planet. Sci. 46, 1169-1194.

Hacker, B. R., G. A. Abers, and S. M. Peacock (2003). Subduction factory, 1 , theoretical mineralogy, densities, seismic wave speeds, and $\mathrm{H}_{2} \mathrm{O}$ contents, J. Geophys. Res. 108, no. B1, 2029, doi: 10.1029/2001JB001127.

Hansen, R. T. J., M. G. Bostock, and N. I. Christensen (2012). Nature of the low velocity zone in Cascadia from receiver function waveform inversion, Earth Planet. Sci. Lett. 337/338, 25-38.

Hyndman, R. D., and K. Wang (1993). Thermal constraints on the zone of major thrust earthquake failure: The Cascadia subduction zone, $J$. Geophys. Res. 98, no. B2, 2039-2060. 
Kamei, R., R. G. Pratt, and T. Tsuji (2012). Waveform tomography imaging of a megasplay fault system in the seismogenic Nankai subduction zone, Earth Planet. Sci. Lett. 317/318, 343-353.

Leahy, G. M., J. A. Collins, C. J. Wolfe, G. Laske, and S. C. Solomon (2010). Underplating of the Hawaiian swell: Evidence from teleseismic receiver functions, Geophys. J. Int. 183, 313-329.

Ligorria, J. P., and C. J. Ammon (1999). Iterative deconvolution and receiverfunction estimation, Bull. Seismol. Soc. Am. 89, no. 5, 1395-1400.

Liu, Y., and J. R. Rice (2007). Spontaneous and triggered aseismic deformation transients in a subduction fault model, J. Geophys. Res. 112, no. B09404, doi: 10.1029/2007JB004930.

Lodewyk, J., and D. Sumy (2014). Cascadia Amphibious Array Ocean Bottom Seismograph Horizontal Component Orientations, 2013-2014 OBS Deployments, OBSIP Management Office Incorporated Research Institutions for Seismology.

Lodewyk, J., A. Frassetto, A. Adinolfi, and B. Woodward (2014). Cascadia Amphibious Array Ocean Bottom Seismograph Horizontal Component Orientations, 2011-2012 OBS Deployments, Version 3.0, OBSIP Management Office Incorporated Research Institutions for Seismology.

McCaffrey, R., R. W. King, S. J. Payne, and M. Lancaster (2013). Active tectonics of northwestern U.S. inferred from GPS-derived surface velocities, J. Geophys. Res. 118, 1-15.

McCrory, P. A., J. L. Blair, F. Waldhauser, and D. H. Oppenheimer (2012). Juan de Fuca slab geometry and its relation to WadatiBenioff zone seismicity, J. Geophys. Res. 117, no. B09306, doi: 10.1029/2012JB009407.

Nedimovic, M. R., R. D. Hyndman, K. Ramachandran, and G. D. Spence (2003). Reflection signature of seismic and aseismic slip on the northern Cascadia subduction interface, Nature 424, 416-420.

Nelson, A. R., B. F. Atwater, T. Bobrowsky, L.-A. Bradley, J. J. Clague, G. A. Carver, M. E. Darienzo, W. C. Grant, H. W. Krueger, R. Sparks, T. W. Stafford Jr., and M. Stuiver (1995). Radiocarbon evidence for extensive plate-boundary rupture about 300 years ago at the Cascadia subduction zone, Nature 378, 371-374.

Nicholson, T., M. Bostock, and J. F. Cassidy (2005). New constraints on subduction zone structure in northern Cascadia, Geophys. J. Int. 161, 849-859.

Oleskevich, D. A., R. D. Hyndman, and K. Wang (1999). The updip and downdip limits to great subduction earthquakes: Thermal and structural models of Cascadia, south Alaska, SW Japan, and Chile, J. Geophys. Res. 104, no. B7, 14,965-14,991.

Parsons, T., A. M. Trehu, J. H. Luetgert, K. Miller, F. Kilbride, R. E. Wells, M. A. Fisher, E. Flueh, U. S. ten Brink, and N. I. Christensen (1998). A new view into the Cascadia subduction zone and volcanic arc: Implications for earthquake hazards along the Washington margin, Geology 26, no. 3, 199-202.

Parsons, T., R. E. Wells, M. A. Fisher, E. Fleuh, and U. S. ten Brink (1999). Three-dimensional velocity structure of Siletzia and other accreted terranes in the Cascadia forearc of Washington, J. Geophys. Res. 104, no. B8, 18,015-18,039.
Rondenay, S., M. G. Bostock, and J. Shragge (2001). Multiparameter two-dimensional inversion of scattered teleseismic body waves, 3 : Application to the Cascadia 1993 data set, J. Geophys. Res. 106, 30,795-30,808.

Saffer, D. M., and H. Tobin (2011). Hydrogeology and mechanics of subduction zone forearcs: Fluid flow and pore pressure, Annu. Rev. Earth Planet. Sci. 39, 157-186.

Savage, M. K. (1998). Lower crustal anisotropy or dipping boundary? Effects on receiver functions and a case study in New Zealand, J. Geophys. Res. 103, no. 7, 15,069-15,087.

Sheehan, A. F., G. A. Abers, C. H. Jones, and A. L. Lerner-Lam (1995). Crustal thickness variations across the Colorado Rocky Mountains from teleseismic receiver functions, J. Geophys. Res. 100, 20,391-20,404.

Silver, P. G., and W. W. Chan (1991). Shear wave splitting and subcontinental mantle deformation, J. Geophys. Res. 96, no. B10, 16,429-16,454.

Stachnik, J. C., A. F. Sheehan, D. W. Zietlow, Z. Yang, J. Collins, and A. Ferris (2012). Determination of New Zealand ocean bottom seismometer orientation via Rayleigh-wave polarization, Seismol. Res. Lett. 83, 704-712.

Toomey, D. R., R. M. Allen, A. H. Barclay, S. W. Bell, P. D. Bromirski, R. L. Carlson, X. Chen, J. A. Collins, R. P. Dziak, B. Evers, et al. (2014). The Cascadia Initiative: A sea change in seismological studies of subduction zones, Oceanography 27, no. 2, 138-150.

Trehu, A. M., I. Asudeh, T. M. Brocher, J. H. Luetgert, W. D. Mooney, J. L. Nabelek, and Y. Nakamura (1994). Crustal architecture of the Cascadia forearc, Science 266, no. 5183, 237-243.

Webb, S. C., and W. C. Crawford (2010). Shallow-water broadband OBS seismology, Bull. Seismol. Soc. Am. 100, 4, 1770-1778

Webb, S. C., A. H. Barclay, D. Gassier, and T. Koczynski (2013). Seismic observations in shallow water, presented at 2013 Fall Meeting, AGU, San Francisco, California, 9-13 December, Abstract S12A-02.

Helen A. Janiszewski Department of Earth and Environmental Sciences Lamont Doherty Earth Observatory of Columbia University 61 Route $9 W$ Palisades, New York 10964 U.S.A. helenj@ldeo.columbia.edu

Geoffrey A. Abers
Department of Earth and Atmospheric Sciences
Cornell University
4126 Snee Hall
Ithaca, New York 14853 US A

Published Online 19 August 2015 